\title{
ALGUNAS CONSIDERACIONES SOBRE LAS RELACIONES ENTRE DERECHO E INTEGRACIÓN SOCIAL EN EL ULTIMO HABERMAS ${ }^{1}$
}

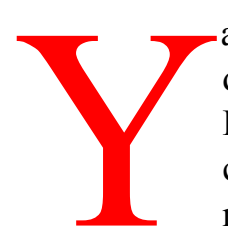
a en su producción de los últimos años, se había venido constatando el interés del filósofo alemán Jürgen Habermas por las cuestiones relativas al mundo del Derecho y del Estado. La última obra ${ }^{2}$ de Habermas viene a marcar la culminación de la vertiente práctica de su filosofía. Está consagrada a la reconstrucción sistemática del papel que las categorías de Derecho y democracia representan en el bagaje conceptual de nuestras sociedades. Examinaré el funcionamiento de ambos conceptos en la arquitectónica del Estado de Derecho con una visión que pretende ser crítica acerca de algunas de las presuposiciones implícitas en estos análisis.

El problema central sigue siendo en este libro, como ya lo fue en la Teoría de la Acción comunicativa, el de la creación del orden social, o con otra formulación, el de la garantía de una integración social que preserve un funcionamiento sin fricciones de la vida democrática de nuestras sociedades. El problema de la integración social ya recibió respuesta cumplida en las páginas centrales de su compendio del $81^{3}$, pero ha merecido un tratamiento nuevo y más afinado, $\mathrm{y}$

${ }^{1}$ Este trabajo, sólo una tentativa, espero que no demasiado frustrada, constituye una incursión sobre temas que son tratados más exhaustivamente en el marco de una tesis doctoral en curso sobre el pensamiento jurídico-político de este pensador alemán.

${ }^{2}$ Faktizität und Geltung. Primera edición. Frankfurt, Suhrkamp, 1992. Existen intentos anteriores de formular un pensamiento jurídico en algunos artículos, ver así «Towards a Communication-Experiment» en Ratio Iuris, Vol. 2, N. ${ }^{\circ}$ 2, julio 1989, págs, 144-154. También «Wie ist Legitimität durch Legalität moglich?» en Kritische Justiz, 20, 2987, I, págs. 1-16 (trad. castellana de Manuel Jiménez Redondo, «¿Cómo es posible la legitimidad por vía de legalidad?» en Escritos de Moralidad y Eticidad, Barcelona, Paidós, 1991, págs. 131-172.

${ }^{3}$ Más concretamente, en el tomo segundo. Ver Theorie des kommunikativen Handelns, Frankfurt, Suhrkamp. Cuarta edición (revisada), 1987 (trad. castellana, Teoría de la Acción Comunicativa, tomo segundo, Madrid, Alianza, 1987. 
ello a causa del descubrimiento de la centralidad de la categoría de Derecho en nuestras sociedades de capitalismo avanzado.

En la Teoría de la Acción comunicativa, el Derecho se adscribe a dos esferas irreconciliables en sus pretensiones mutuas: las del sistema y el mundo de la vida. Por lo que se refiere al mundo de la vida, entendido como horizonte aproblemático y fuente de las interpretaciones en las acciones de los individuos, el Derecho ha de ser considerado como un orden normativo junto a otros, encuadrado en el componente social-institucional. En esa medida, su labor consistiría en la creación de integración social y la acreditación de la solidaridad entre los miembros del colectivo ${ }^{4}$. Conviene no desdeñar las funciones que el Derecho está llamado a realizar en las otras dos esferas del mundo de la vida: en el plano de la cultura, el Derecho se presenta como un sistema de símbolos, transmisible, formador de tradiciones jurídicas y constitucionales con que opera la comunidad de los agentes; en el plano de las estructuras de la personalidad, el Derecho se emplea en la tarea de crear competencias y disposiciones favorables en los individuos, fomentando con ello un comportamiento conforme con las representaciones normativas del grupo ${ }^{5}$.

La integración social se logra en primer plano, y de forma natural, sobre la base representada por las acciones comunicativas, esto es, merced a la coordinación contra el trasfondo representado por el consenso. El consenso está instalado en el lenguaje cotidiano, el cual posee la ventaja de la multifuncionalidad frente a los lenguajes especializados. Es menester llamar la atención sobre el hecho de que el consenso es un recurso poco previsible y extremadamente fortuito, motivo por el que se presenta como un fundamento poco fiable sobre el que establecer la coordinación de las interacciones ${ }^{6}$. En la absorción de los riesgos que implica un disenso potencial ${ }^{7}$, es donde el Derecho juega un papel de importancia central, cumpliendo así una integración reflexiva, o de segundo orden. Habermas nos recuerda que frente al riesgo de despliegue de las acciones comunicativas, el Derecho reacciona imponiendo una doble táctica de liberación y limitación de la comunicación, de estabilización de los comportamientos con expresa interdicción del análisis de los motivos de la obediencia, y extensión irrestricta de los discursos en cuestiones de fundamentación de las normas.

${ }^{4}$ Teoría de la Acción comunicativa, págs. 200-206.

${ }^{5}$ Faktizität und Geltung, pág. 108.

${ }^{6}$ Faktizität und Geltung, págs. 28-45.

${ }^{7}$ Inscrito con igual legitimidad que el consenso en el telos del lenguaje, como nos recuerda Wellmer: «Konsens als Telos der sprachlichen Kommunikation?», en Kommunikation und Konsens in modernen Gesellschaften, Frankfurt, Suhrkamp, 1992, pág. 22. 
Es en este sentido en el que hablamos de «regulación normativa de las interacciones estratégicas» ${ }^{8}$, conciliando de esta manera dos orientaciones en la coordinación de las acciones que se presentan como irreductibles a los ojos de los agentes. Las normas ejercen así su virtualidad integrativa cumpliendo dos condiciones: la de representar limitaciones fácticas, con las que el actor cuente para la adaptación objetivamente funcional de su comportamiento, a la vez que imponen obligaciones, justificables únicamente a la luz de pretensiones de validez intersubjetivamente reconocidas. La integración social se consigue provocando una disposición a la obediencia a través de la coacción jurídica, y por la validez legítima de las normas a un tiempo. Esta doble referencia está presente a manera de síndrome en la validez de las normas jurídicas, con la vinculación indisoluble entre los principios de positivación y fundamentación o legitimidad'.

Con el binomio compuesto sobre la relación integración-legitimidad, se desmiente la imagen positivista que equiparaba Derecho y voluntad del legislador. La cualidad racional de la legislación depende de la voluntad coincidente y unida de todos los ciudadanos, en cuanto consideramos libres e iguales. Los destinatarios individuales de las normas jurídicas sólo pueden ser cohesionados si se reconocen tras ellas, esto es, si participan como artífices en la creación del sistema del Derecho ${ }^{10}$. En esa medida, nos dirá Habermas, el Derecho moderno se alimenta de la solidaridad que se concentra en el papel de ciudadano y procede en última instancia de la acción comunicativa. La integración social surge de la garantía de la coexistencia de iguales libertades de arbitrio de los ciudadanos, y del reconocimiento paralelo de derechos recíprocos. Para ello se precisa del concurso del legislador político ${ }^{11}$, que se constituye en referencia necesaria para las tareas integrativas, demandando de los sujetos miembros la adopción de un papel participante en la labor de la generación de principios normativos con ayuda de los que regular la convivencia. La integración social pilotada por el sistema jurídico va indisolublemente asociada a la idea democrática, entendida ésta como impulso cohesivo albergado en la voluntad coincidente de la ciudadanía. Sólo la autolegislación puede constituirse en garantía de la estabilidad social, con lo que se cierra el círculo que va desde la acción comunicativa hasta el sistema político-jurídico.

Analicemos de forma más cercana la articulación del plano del mundo de la vida, el Derecho y el sistema de gobierno como se plantea en la última obra de Habermas.

${ }^{8}$ Faktizität und Geltung, págs. 55-56.

${ }^{9}$ Faktizität und Geltung, págs. 48-49.

${ }^{10}$ Faktizität und Geltung, págs. 50-526.

${ }^{11}$ Faktizität und Geltung, pág. 50. 
Para el Habermas de Faktizität und Geltung, el mundo de la vida racionalizado y desencantado encuentra su realización en la forma de la sociedad civil. Esta se concibe como el conjunto de las asociaciones y los acuerdos de carácter no económico y no estatal que anclan las estructuras de comunicación de la publicidad política en el componente social del mundo de la vida. La función de los movimientos, asociaciones y organizaciones que transitan esta esfera civil es la condensación, asunción y amplificación de la resonancia de los problemas que advienen a la órbita privada, transmitiéndolos a la publicidad política ${ }^{12}$. Es importante hacer notar la importancia que la neutralización del poder social tiene en la constitución de la sociedad civil. Habermas usa la expresión «poder social» para «indicar la medida de posibilidad de que un actor imponga sus intereses en las relaciones sociales contra la oposición de los demás ${ }^{13}$. La sociedad civil ha de ser capaz de rebajar este gradiente de poder, consiguiendo que se exprese sólo en tanto posibilite el ejercicio, y no la restricción, de la autonomía ciudadana.

La constitución de la sociedad civil viene estimulada por la implantación de los derechos fundamentales ${ }^{14}$ los cuales garantizan la preservación de un espacio para la formación privada de la conciencia y el juicio, en suma, para la protección de la privacidad. Pero no basta este baluarte constitucional para preservar la vitalidad de la sociedad civil, sino que es menester recurrir a su inmersión en el seno de una cultura política libre y del correspondiente patrón socializatorio, esto es, de un mundo de la vida racionalizado.

La sociedad civil recoge y amplifica las voces del público, cuyos individuos padecen los costes externalizados de los sistemas sociales en tanto reobran contra su mundo de vida. Funciona como depósito de gravámenes y agravios ${ }^{15}$, pero sin provocar una disposición inmediata al ejercicio de influencia, y mucho menos la adopción de decisiones vinculantes para la vida del colectivo ${ }^{16}$.

Para ello se precisa el establecimiento de la esfera de la «publicidad política» (politische Öffenlichkeit). La publicidad se entiende como un sistema de alarma con sensores no especializados, pero sensibles a lo largo y ancho de todo el tejido social. Lo relevante en esta estructura son los criterios formales que diseña para el acaecimiento de una opinión pública cualificada. La publicidad, nos dirá

${ }^{12}$ Faktizität und Geltung, págs. 433 y 444 . He elegido la traducción «publicidad» o para el término alemán «Öffenlichkeit», entendida claro está como «esfera de lo público».

${ }^{13}$ Faktizität und Geltung, pág. 215.

${ }^{14}$ Faktizität und Geltung, pág. 447.

${ }^{15}$ Faktizität und Geltung, pág. 441.

${ }^{16}$ Faktizität und Geltung, pág. 437. 
Habermas, es un espacio en el cual se liberan los flujos comunicativos de todos los sujetos en tanto tratan de informarse sobre una praxis común, y en esta medida conforma la antesala de la formación de opiniones específicas sobre temas de relevancia general y colectiva ${ }^{17}$. Lo fundamental es caer en la cuenta de que la publicidad política es un recurso que no puede ser creado discrecionalmente por el poder político y los partidos en liza, ni manipulada, so pena de enfrentarnos a un público movilizado plebiscitariamente del que quepa esperar tan sólo un asentimiento ciego y reflejo a los condicionamientos del poder ${ }^{18}$.

En el interior de la publicidad política, se articulan miríadas de opiniones públicas particulares sobre problemas de relevancia acreditada para la vida del colectivo. Estas opiniones, al contrario de lo que sucedía en la base privatista de la sociedad civil, sí que representan ya potenciales de influencia de cara a los interlocutores del poder ${ }^{19}$.

Hasta ahora hemos centrado nuestra atención en la esfera informal de formación de la opinión colectiva. En el esquema establecido por Peters, y usufructuado por Habermas, vendríamos a situarnos en el plano de la así llamada «periferia» ${ }^{20}$. La importancia de la periferia es, paradójicamente, central a la hora de abordar el problema de la integración social, pues la legitimidad de las decisiones, nos dirá Habermas, depende de los procesos de formación de la opinión que tiene lugar en esta instancia informal y previa ${ }^{21}$. El núcleo institucional tiene importancia en las tareas integrativas de una manera derivada, y sólo en tanto permanece vinculado a los influjos informales de las publicidades políticas.

El problema que entraña un concepto de integración social que trate de obrar sin el auxilio de la política y el Derecho es el de la posibilidad de una «socialización comunicativa pura ${ }^{22}$. En esta ficción, la reproducción social se hace recaer en los procesos de entendimiento y en las acciones comunicativas, en las tomas de postura de los individuos ante pretensiones de validez que les advienen. Pero una construcción como ésta no puede dar razón de los costes de información y

${ }^{17}$ Faktizität und Geltung, págs. 437, 438.

${ }^{18}$ Faktizität und Geltung, págs. 434, 435.

${ }^{19}$ Faktizität und Geltung, pág. 439.

${ }^{20}$ Bernhard Peters, Die Integration moderner Gesellschaften. Frankfurt, suhrkamp, 1933, pág. 327.

${ }^{21}$ Faktizität und Geltung, págs. 431 y 432.

${ }^{22}$ Se trata de nuevo de un préstamo de la obra ya citada de Peters. Die Integration moderner Gesellschaften, págs. 230-236. Lo mismo que para Habermas, también para Peters estamos ante una idealización, y se cuida a su vez de no imputarle tal resultado al pensador de Frankfurt. 
decisión de los cursos comunicativos ${ }^{23}$, de las capacidades cognitivas limitadas de los sujetos de las comunicaciones, de la distribución desigual de la atención, las competencias y el conocimiento en el público. Asimismo, permanece ciego frente al etnocentrismo, las debilidades de la voluntad, la irracionalidad y el autoengaño ${ }^{24}$. A ello se añade la escasez de los recursos funcionalmente necesarios de los que dependen en muy alto grado los procesos deliberativos de formación de la voluntad y la opinión colectivas. Como puede apreciarse, Habermas considera las limitaciones que los imperativos funcionales impuestos a los sistemas de acción orientados por el recurso del entendimiento, con lo que se mitiga la distinción férrea que establecía en la Teoría de la Acción comunicativa entre sistema y mundo de la vida ${ }^{25}$.

El Derecho aparece a la luz de estas restricciones como una realidad necesaria, como un «factum» que no puede ser obviado en el curso de un feliz proceso de evolución social, al término del cual podrían suprimirse las formas de dominación y los instrumentos de que se nutren, a la manera de las utopías marxianas de la sociedad futura. El Derecho sirve a la reducción de la complejidad social, es un medio insoslayable de traducción de las relaciones de reconocimiento que se albergan en el mundo de la vida a la realidad de los imperativos sistémicos de la política y la economía, elaborando en el medio del lenguaje cotidiano requerimientos de distintas procedencias ${ }^{26}$. Pero conviene no olvidar que el Derecho impone unas limitaciones estructurales insoslayables, en cuanto a cargas de legitimación, que hacen que el mundo de la vida, y la sociedad civil en que se vertebra, se hagan valer en cualesquiera contextos funcionales. Ello explica la aparición de disonancias cognitivas entre las suposiciones de validez del Estado de Derecho y las formas fácticas en que el poder político se desenvuelve. Esto, y no otra cosa, es lo que Habermas entiende como tensión externa entre factividad y valide $z^{27}$.

${ }^{23}$ Ver a este respecto las observaciones de Giegel, en su artículo «Diskursive Verständigung und systemische Selbststeuerung», págs. 68-73, en el libro colectivo de Hans-Joachim Giegel (compilador) Kommunikation und Konsens in moderner Gesellschaften, Frankfurt, suhrkamp, 1992.

${ }^{24}$ Faktizität und Geltung, pág. 396.

${ }^{25}$ Amén del hecho de que Habermas ha mitigado también la correlación estricta entre acción comunicativa e integración social, y acción estratégica e integración sistémica, tal y como pueda verse en su «Entgegnung», publicada en el volumen colectivo editado por Axel Honneth y Hans Joas Kommunikatives Handeln, Frankfurt, suhrkamp, 1986, págs. 380-384, o en Nachmetaphysisches Denken, Frankfurt, suhrkamp, 1988, págs. 63-104 (hay traducción castellana de Manuel Jiménez Redondo Pensamiento postmetafísico, Madrid, Taurus, 67-107.

${ }^{26}$ Faktizität und Geltung, págs. 77, 78, 103.

${ }^{27}$ Faktizität und Geltung, pág. 58. 
En contra del sistema ${ }^{28}$, la primacía de los análisis del mundo de la vida puede establecerse sobre el suelo del concepto de «poder comunicativo» y el proceso que se pone en marcha en torno suyo. El poder comunicativo ${ }^{29}$ se manifiesta en las ordenaciones que protegen la libertad política; en la resistencia contra las fuerzas que amenazan la libertad política, interna o externamente; y en aquellos actos revolucionarios que fundan nuevas instituciones de libertad ${ }^{30}$. Surge de la capacidad de entenderse, y se despliega en el espacio de la publicidad política informal. Con ayuda de este concepto, entendemos la creación de Derecho legítimo, y del mismo poder político ${ }^{31}$, diferenciándolo de su uso administrativo. El poder comunicativo actúa a la manera de un cerco de razones normativas, cuyo acceso constructivo o reconstructivo está vedado a los titulares del poder administrativo. Es merced a la circulación del poder administrativo. Es merced a la circulación del poder comunicativo sobre la aplicación racional y los procedimientos de ejecución administrativos de los programas legales por todo el cuerpo social, como se desarrolla una fuerza de integración social, ya sea estabilizando los comportamientos, ya realizando metas colectivas.

Hasta ahora, creo que podríamos hablar de una legitimación material del sistema jurídico y político, haciendo con ello justicia a la dependencia del mundo de la vida racionalizado y los flujos de opinión que de él parten. El proceso comunicativo de la constitución del poder surgiría de la sociedad civil, y llegaría precipitado en forma de poder comunicativo, tras atravesar las esclusas de la esfera de la publicidad política y la formación de opiniones públicas puntuales.

${ }^{28}$ No estamos desdeñando, como ya trataremos de explicar más adelante, la perspectiva sistemática en el análisis de las realidades jurídicas, pero parece justo resaltar el énfasis que frente a los enfoques funcionalistas, Habermas pone en la primacía del mundo de la vida. Esto recibe una confirmación palmaria en este párrafo extraído de la página 60: «las tareas de integración sistémica han de permanecer conectadas y acopladas, merced a la autocomprensión constitucional de la comunidad jurídica, al proceso de integración social de la praxis ciudadana de autodeterminación».

${ }^{29}$ El concepto de «poder comunicativo» está tomado de la pensadora Hannah Arendt. Fue utilizado por primera vez por Habermas en un artículo del año 1971 titulado «El concepto de poder de Hannah Arendt», publicado en el libro Perfiles filosófico-políticos, trad. castellana de Manuel Jiménez Redondo, Madrid, Taurus, 1975, págs. 205-222.

${ }^{30}$ Faktizität und Geltung, págs. 182-187. También en «Volkssouveranität als Verfahren», pág. 626 ahora contenido en el libro citado de Habermas como apéndice.

${ }^{31}$ Se trata, está claro, de un concepto normativo, y no descriptivo del poder político, frente al que se alza tozuda la realidad en la que se impone un contraproceso en el que se vinculan el poder social de los agentes y las organizaciones poderosos con un concentrado emancipado del poder administrativo. 
Y sin embargo, siendo esto así, Habermas parece apoyarse en una segunda acepción de integración, más centrada en los procesos políticos del núcleo, esto es, institucionalizados $\mathrm{y}$ formales, que en los de la periferia del sistema ${ }^{32}$. Estamos ante un desplazamiento de los flujos comunicativos débiles y anárquicamente liberados con cada espasmo de las luchas sociales, hacia los procedimientos que encuentran expresión en las formas del Estado de Derecho moderno.

El Estado de Derecho surge de la necesidad de institucionalizar un sistema de equilibrios entre los tres poderes de la integración social entendida de una forma general: el dinero, el poder y la solidaridad ${ }^{33}$.

La voluntad política es expresión de las intuiciones morales del grupo, así como de las formas de vida compartidas, y de determinados fines e intereses pragmáticamente elegidos $^{34}$. Analicemos con más cercanía estos usos de la razón práctica.

Las cuestiones pragmáticas tratan de la ponderación racional de los fines a la luz de los valores aceptados. Tan pronto como los valores que subyacen a las máximas medios-fines son problematizados, las decisiones se miden sobre el trasfondo del fin absoluto de una dirección auténtica de la vida. En las cuestiones morales, por último, se impone el punto de vista normativo bajo el que probamos cómo podemos regular nuestra convivencia en interés igual de todos. Una norma es justa, en ese sentido, cuando todos pueden querer que sea seguida por cualquiera en una situación equivalente. Junto a esta estructura de usos de la razón práctica, nos topamos con las negociaciones de intereses, a la que apelamos cuando no es posible composición consensual alguna entre las partes, y hemos de darnos por satisfechos con un acuerdo entre posturas irreductibles. En las negociaciones, las relaciones sociales de poder no pueden resultar neutralizadas, por lo que nos resta, sino conformamos con la moderación del procedimiento por la aplicación de principio de equidad.

Pues bien, para Habermas la estructura del Estado de Derecho se entiende como la institucionalización jurídica de la red de negociaciones y discursos arriba detallados ${ }^{35}$, en la medida en que la formación política discursivamente articulada haya de realizarse en formas

\footnotetext{
${ }^{32}$ En el capítulo cuarto de Faktizität und Geltung, consagrado a la arquitectónica del Estado de Derecho. Puede verse también la segunda de las conferencias de las «Tanner Lectures on Human values», ahora traducidas al alemán como apéndice del libro de Habermas, págs. 571-599. Asimismo, en el artículo citado en la nota 1.

${ }^{33}$ Faktizität und Geltung, págs. 187.

${ }^{34}$ Para las consideraciones siguientes me remito al apartado II, del capítulo cuarto de Faktizität und Geltung, págs. 187-207.

${ }^{35}$ Faktizität und Geltung, pág. 209.
} 
de comunicación en las que la pregunta por el qué debemos hacer pueda ser respondida de forma racional bajo diferentes aspectos.

Estamos, recordémoslo una vez más, en la sede formal de las investigaciones en torno a la legitimidad; pero esa vertiente formal demanda de suyo la consideración de la informal, lo que se advierte como una exigencia de la misma lógica de los discursos y las negociaciones $^{36}$. Las cuestiones éticas poseen una referencia insustituible a la identidad de la forma de vida a la que los individuos tratan de entenderse pertenecen, por lo que no es factible postular una desconexión del discurso correspondiente de los contextos sociales. Las cuestiones morales presuponen la potencialidad de la aparición de conflictos de intereses que precisen de una regulación consensual bajo puntos de vista de justicia, por lo que la base social tampoco puede ser neutralizada. Ello se intensifica al hablar de las negociaciones, en las cuales la facticidad de las tomas de posición y la disparidad de los intereses en liza se manifiesta más palpablemente. Así es como se postularía la reconexión entre ambas acepciones de la integración, salvando la tensión que parecía reconocerse tras su dialéctica.

Hasta aquí lo que se refiere al plano del mundo de la vida y al rol que el Derecho desarrolla en su interior. Unas líneas bastarán para apuntar algunas de los problemas con que se topa el fenómeno de lo jurídico en la consideración del otro polo, el referido al sistema ${ }^{37}$. En la vertiente sistémica, el Derecho se entiende como medio de organización de los mensajes de la Administración y del mercado. Pero a diferencia de las consideraciones vertidas en la Teoría de la Acción comunicativa, el Derecho no constituye de por sí una amenaza que se cierna sobre el mundo de la vida, imponiendo su asimilación a recursos que le resulten extraños, en forma de lo que se entendió como

${ }^{36}$ Faktizität und Geltung, pág. 211.

${ }^{37}$ Ya en el capítulo primero de la obra de referencia, Habermas reconoce la necesidad como antes lo hizo en la Teoría de la Acción comunicativa, de complementar el análisis del Derecho en sus dos vertientes. Ver Faktizität und Geltung, págs. 58-60. Autores como el mismo Peters ya citado, prefieren hablar de modelos de socialización intencionales (mundo de la vida) o no intencionales (sistema), en lugar de hacerlo de dos modos de integración social general. Peters, op. cit., págs. 87 y 88. La distinción ha perdido su nitidez, y con ella la que se establecía entre el Derecho como institución y el Derecho como medio. El mismo Habermas reconoce haberla abandonado siguiendo sugerencias de Karlo Tuori: en la nota 92, pág. 507. Sin embargo, creo que esto no es del todo así, como se deduce de la aseveración contenida en la página 428 , cuando admite que en el caso de la constitucionalización de los sistemas de acción ésta significa algo distinto en el caso de las organizaciones y en el de ámbitos como el de la familia o la escuela. «En el primero de ellos, el Derecho conforma (überformt) las relaciones reguladas en las instituciones existentes; en el segundo, sirve a la coordinación funcional de relaciones jurídicamente creadas» (el subrayado es mío). 
juridificación (Verrechtlichung) ${ }^{38}$. Por el contario, en Faktizität und Geltung parece abrirse paso una visión positiva del Derecho, en su función de valedor del mundo de la vida frente a los imperativos del sistema. La misma forma jurídica de la que sirven los subsistemas funcionales para emitir sus mensajes, les impone ya restricciones estructurales de fondo, en concreto, la atención a un cúmulo de razones normativas y la necesidad de fundamentación de las decisiones, lo que pone en suspenso la desnuda arbitrariedad de los poderes económico y político.

Pero ciertamente, existen rasgos que parecen abonar una interpretación funcionalista o sistémica de lo jurídico. La coexistencia de la positivación junto con el principio de fundamentación, parece asegurar al Derecho un puesto entre los sistemas en los que se han diferenciado las sociedades modernas. Al fin y al cabo, el Derecho también se rige por un código especial, el que se articula en torno a la dicotomía lícito/ilícito ${ }^{39}$; también la autorreferencialidad de las comunicaciones que se registran en su interior parece avalar su condición separada de otros ámbitos. Lo mismo podríamos decir de la consideración de sus virtualidades para conseguir la estabilización de los comportamiento de los sujetos destinatarios, al margen de los motivos que éstos pudieran aducir para la obediencia, sobre la base del mero expediente de la amenaza de sanciones. Entender el Derecho como restricción, como conjunto de datos a los que el actor ha de adaptar objetivamente su conducta, abre la perspectiva del observador ${ }^{40}$ que calcula las consecuencias egocéntricamente, y deja al margen las posibilidades virtuales de entenderse. En este aspecto del Derecho como mecanismo para la coordinación funcional de las acciones, como garante de una socialización no intencional, parece leerse un sesgo sistémico claro. Habermas no presta la suficiente atención a estos aspectos en sus consideraciones sobre lo jurídico, ni a los fenómenos de jurisdicción reificante que siguen produciéndose como resultado de las intervenciones del Estado social, suministrador de prestaciones a cambio de la lealtad clientelar de las masas ${ }^{41}$.

${ }^{38}$ Teoría de la Acción Comunicativa, págs. 514-527.

${ }^{39}$ Esa es la tesis de la teoría de los sistemas. Ver, como ejemplo paradigmático, Luhman Die soziologische Beobachtung des Rechts, Frankfurt, Alfred Metzner, 1986, págs. 38-44. Del mismo Frankfurt, suhrkamp, 1993, capítulo cuarto, págs. 165-213.

${ }^{40}$ Faktizität und Geltung, pág. 44.

${ }^{41}$ He creído percibir una despreocupación en los análisis de Habermas sobre los peligros que se encierran en las intervenciones juridificantes del Estado de Bienestar, si bien reconoce el fracaso paradigma jurídico que sostiene en el capítulo noveno del libro. En la Teoría de la Acción Comunicativa se estaba más presto a la denuncia de las consecuencias reificantes de la utilización instrumental del Derecho. 
Por último, trataré de dejar apuntados dos problemas a los que se enfrenta un intento como el de Habermas de hacer residir los procesos de integración social en los rendimientos conscientes de los individuos, o en las labores pilotadas intencionalmente por el sistema político-jurídico.

El Derecho garantiza una autonomía privada o «libertad comunicativa», que puede ser entendida como liberación de las obligaciones que entraña la acción orientada al entendimiento. La libertad comunicativa así generada puede ser entendida como la posibilidad, recíprocamente reconocida en la acción orientada al entendimiento, de tomar postura frente a las manifestaciones de un oponente y las correspondientes pretensiones de validez que se erigen ${ }^{42}$. En este sentido, la autonomía privada de un sujeto puede entenderse como la libertad negativa a retrotraerse del campo público de las obligaciones ilocucionarias recíprocas a la posición de observación e influencia. El problema está en garantizar que las libertades comunicativas de los sujetos privados van a emplearse en la empresa común de autolegislación, sobre la base de intereses compatibilizados, de interpretaciones comunes, de representaciones concordadas de la vida buena y de la identidad colectiva, y de valores generalizados por vía discursiva. ¿Por qué habríamos de entrar en discursos garantes del entendimiento, en lugar de recurrir a coordinaciones funcionales sobre la base del cálculo egoísta de las utilidades? El problema no es nuevo, y expresa una crítica, ya convertida en lugar común, a los déficits motivacionales de la ética del discurso, y de las propuestas habermasianas en general $^{43}$.

En el campo de la ética del discurso, Habermas trata de dar respuesta a la indeterminación motivacional argumentando que las ideas morales no tendrían ningún peso en la práctica si no pudiesen apoyarse en la fuerza impulsora que les proporcionan los motivos y en la vigencia social de las instituciones reconocidas ${ }^{44}$. En este sentido,

${ }^{42}$ Faktizität und Geltung, pág. 152.

${ }^{43}$ Habermas trata de dar respuesta a estas críticas en sus escritos relativos a la ética del discurso. Por citar los más conocidos o los más recientes, ver Moralbewusstsein und kommunikatives Handeln, 4. ${ }^{\text {a }}$ edición revisada, Frankfurt, suhrkamp, artículos «Treffen Hegels Eiwnwände gegen Kant auch auf die Diskursethik zu?», op. cit., págs. 9-30 y«Gerechtigkeit und Solidarität», en el mismo volumen, págs. 49-76. Existe traducción castellana de Manuel Jiménez Redondo con el título «¿Afectan las objeciones de Hegel a Kant también a la ética del discurso?», en Escritos de Moralidad y Eticidad, págs. 97-130 por lo que hace el primero de ellos; y del segundo, a cargo de Julio de Zan bajo el título «Justicia y solidaridad», en el volumen colectivo editado por K. O. Apel, A. Cortina y otros Ética Comunicativa y Democracia, Barcelona, Crítica, 1991, págs. 175-205.

${ }^{44}$ «iAfectan las objeciones..., pág. 122. 
toda moral universalista depende del sostén y el apoyo que encuentre en las formas de vida, de la concordancia con prácticas de socialización y educación que pongan en marcha en los sujetos controles de conciencia fuertemente internalizados y fomenten identidades del yo relativamente abstractas. Una moral universalista precisa también de cierta concordancia con instituciones sociales y políticas en las que ya estén encarnadas ideas jurídicas y morales de tipo postconvencional. La plasmación de principios morales en las formas de vida concretas no depende de la marcha del Espíritu Absoluto hegeliano, sino sobre todo de los esfuerzos y sacrificios colectivos de los movimientos sociales y políticos a lo largo y ancho de la Historia ${ }^{45}$.

La respuesta por lo que se refiere al dominio del Derecho no puede apartarse de esas premisas. Habermas propone siguiendo esta línea un modo de entender la práctica de los asuntos públicos que llama «política deliberativa» ${ }^{46}$. La política deliberativa constituye el núcleo del proceso democrático. Este procedimiento crea una relación interna entre las consideraciones pragmáticas, los compromisos, y los discursos de autocomprensión (éticos) y de justicia, y funda la suposición de que bajo las condiciones de un flujo de información relativa al problema, y una elaboración correcta de la misma, pueden ser alcanzados resultados racionales o equitativo $\mathrm{s}^{47}$. El progreso de la política deliberativa se hace depender de la institucionalización de los procedimientos y suposiciones de la comunicación, así como de la interacción entre las deliberaciones formalmente establecidas y las opiniones públicas informales ${ }^{48}$. Junto con la vertiente de la institucionalización, y paralelamente al caso de la moral, hemos de contar con el expediente de la socialización discursiva de la comunidad jurídica. La política deliberativa, apunta Habermas, pierde su apariencia extrañada e irreal tan pronto como la consideramos como un proceso de aprendizaje reflexivamente organizado, que descarga los procesos latentes de integración social y los continúa dentro de un sistema de acción especializado ${ }^{49}$. La referencia a las opiniones públicas informales, nos pone sobre la pista de aquellas luchas sociales por el reconocimiento que impulsan el vector histórico en una dirección u otra, y que demandan una actualización siempre renovada del sistema de los derechos a la luz de la nueva comprensión constitucional de la comunidad

${ }^{45}$ «¿Afectan las objeciones...», pág. 122.

${ }^{46} \mathrm{Al}$ estudio de este concepto se consagra completo el capítulo séptimo de Faktizität und Geltung, titulado: «Política deliberativa -un concepto procedimental de la democracia», págs. 349-398.

${ }^{47}$ Faktizität und Geltung, págs. 359-360.

${ }^{48}$ Faktizität und Geltung, pág. 362.

${ }^{49}$ Faktizität und Geltung, pág. 390. 
jurídica. El caso extremo de esta lucha, representado por la desobediencia civil, llama nuestra atención sobre la conexión de los procesos de formación de la voluntad con los procesos de comunicación del mundo de la vida, apelando a los contenidos normativos del Estado de Derecho democrático contra la inercia sistémica de la política institucional ${ }^{50}$.

Así pues, la tensión entre la desintegración que se esconde en la liberación irrestricta de las libertades comunicativas y la integración que se lleva a cabo a su merced, sólo puede conjurarse recurriendo al expediente de una cultura política liberal ${ }^{51}$ en el seno de la sociedad civil, que se constituya en garante de una socialización exitosa en los valores representados por los derechos fundamentales de las democracias, junto con la necesidad de institucionalizar la red de discursos y negociaciones en el plano formal. Pero conviene apuntar que, en el curso de la institucionalización, no puede excluirse a priori, sino que lejos de ello habría de presuponerse la necesidad de apelar al elemento de la coacción. De nuevo se hace perentoria la moderación de los idealismos que la construcción parece imponer. La funcionalidad de potencial de amenazas representa una expediente nada desdeñable a la hora de preservar los recursos del entendimiento frente a las amenazas derivadas de los impulsos atomistas de individuos egoístas. La predisposición a la cooperación no es algo que pueda ser supuesto sin más, sino que las más de las veces ha de venir urgida por vía de imposición de consecuencias desfavorables para el caso de que las inclinaciones egoístas no fueran abandonadas voluntariamente.

El último ítem que trataré es el representado por la dificultad que nos plantea mantener una visión consensual de la reproducción de nuestras sociedades a la vista de la pluralidad irreductible de cursos biográficos y formas de vida. El intento de mediar este maremágnum de visiones a veces contradictorias de los cursos de actuación posibles y deseables parece empujarnos hacia un callejón sin salida. Como nos recuerdan autores como Giegel $^{52}$, no todos los problemas son susceptibles de consenso, pero es que en los casos en que sí parece aplicable este procedimiento, los costes y los riesgos que se generan pueden poner en peligro la reproducción social. El entendimiento bloquea otras actividades, la decisión del establecimiento de discursos no está discursivamente fundada, y se plantean problemas derivados de la inexistencia de un metadiscurso para elucidar la pertinencia de interrumpir o proseguir un discurso ya en funcionamiento. Schimank, por ejemplo, nos habla de la existencia de un disenso

${ }^{50}$ Faktizität und Geltung, pág. 462-464.

${ }^{51}$ Faktizität und Geltung, pág. 449.

${ }^{52}$ Hans-Joachim Giegel, «Diskursive Verständigung...», págs. 68-73. 
general en las orientaciones, y de la imposibilidad de establecer nada más allá de consensos puntuales sobre intereses. Por último, autores como Wellmer ${ }^{53}$ apuntan al hecho de que el concepto de consenso que parece plantear Habermas, parece desarraigarse de las condiciones de la historicidad de los acuerdos particulares, y de la posibilidad de que éstos queden desvirtuados por nuevas circunstancias o en el curso de procesos reflexivos de aprendizaje. Me conformaré con apuntar que quizá todos los consensos corran el peligro potencial de verse disueltos en negociaciones de intereses, y de que presumiblemente sería más realista plantear el consenso como búsqueda del entendimiento, más que como su consumación.

${ }^{53}$ En el artículo ya citado «Konsens als Telos...», pág. 29. 